who turn their attention to apparently analogous conditions in man and animals. It will be useful to the research worker in experimental pathology, and non-veterinarians in particular will find useful the brief descriptions of some of the normal variations which occur in different species of animals. Equally valuable to all are the side-by-side illustrations of some normal and diseased tissues.

Volume 1 presents a fairly detailed account of disease processes affecting bone, joints and synovial membranes. Organ pathology is discussed on a systematic basis and here includes the respiratory, hæmopoietic, endocrine, circulatory, and the genital systems. Volume 2, which is to be published shortly, will deal with the remaining systems and organs of the animal body. There is, rightly, no account of general pathology because, as the authors point out, this subject is adequately covered in many standard text-books. The gross and microscopic structural changes in the various tissues are presented, together with sufficient information on altered function and consequent clinical signs to stimulate and interest the student. The text is well illustrated with photographs and photomicrographs of excellent quəlity which clearly indicate the essential features of the lesion under discussion. A minor criticism here might be that some of the illustrations are wasteful of space, for example, two full-page photographs to show adventitial placentation in the ox.

The excellent bibliography is a major strength of the book. Appended to each chapter are many selected references which will be useful to a wide range of readers. References are given to key papers in the related fields of virology, bacteriology, parasitology, oncology and genetics where these abut on to the main subject of pathology. It is. however, unfortunate that some, at least, of the references are not 'tied in' to the text, because the authors in some of their discussions do not always distinguish between what is fact and what is speculation. This is an obvious drawback from the point of view of the student and the non-specialist reader. The references are well set out and there is a good and accurate index. Typographical errors are rare; the book is well produced and of the high standard associated with the publishers. It is probable, however, that the cost will be prohibitive for many students.

Inevitably in a work so extensive as this there are bound to be omissions, and the relative emphasis placed on some subjeets will not meet with everyone's approval. In the chapter on respiratory disorders, a brief résumé of the modern concepts of the structure of the alveolar epithelium would have helped to clear some of the confusion in the text, and the section dealing with the interstitial pneumonias could, with advantage, be amplified and more attention directed to the pathogenesis of these diseases. Students of comparative pathology will be disappointed with the section on arterial disease. There is no discussion of atherosclerotic lesions in pigs or cattle (but, in fairness to the authors, they do point out that arterial disease is of no economic importance in domestic stock). In their introductory remarks, the authors state that all they have to say on a specific disease is said in one place under the organ system which is most appropriate. They waive this general rule in several places but chiefly in the sections devoted to the genital systems. It is, however, very surprising that in the chapter on the cardio-vascular system no mention is made of the virus of swine fever ('hog cholera') as a major cause of vascular damage in swine and hence as the prime cause of the protean lesions of this important disease. It is probable that swine fever will be described in Volume 2, but the essential lesion is one affecting the small blood vessels and as such should receive attention in this section.

In their preface, the authors do not attempt to justify their book because, as they say, a good book is its own justification. This is such a book; it will find and retain its place on the shelves as an indispensable standard work of reference.

A. R. Jennings

\section{THE DEVELOPING WORLD}

\section{Our Developing World}

By L. Dudley Stamp. Pp. 195. (London: Faber and Faber, Ltd., 1963.) 8s. $6 d$.

HE population of the world to-day is more than $3,000,000,000$, probably almost double the population in 1900. This means that the past sixty years have seen a growth equal to that in the entire previous history of mankind. This sobering thought becomes frightening when we look into the future. In 1951 the United Nations estimated the world population for 1980 as between $2,976,000,000$ and $3,636,000,000$. They revised these figures in 1954 to give estimates between $3,295,000,000$ and $3,990,000,000$ and again in 1958 to between $3,850,000,000$ and $4,280,000,000$.

These figures are quoted by Prof. Dudley Stamp in Our Developing World, and he points out that they show not only that our knowledge of the numbers of mankind is improving, but that they are constantly showing previous estimates to be too conservative. By 1980 world population will probably be considerably more than $4,000,000,000$ and, by the end of the century, between $7,000,000,000$ and $8,000,000,000$. It is difficult to write about the future relationship between population and resources against so dynamic a situation, and Prof. Stamp's experience shows this. The core of his latest book was a series of talks (the Patton Foundation Lectures at Indiana University) published in 1952 as Land for Tomorrow. This was brought up to date for an English edition, in 1953, called Our Undeveloped World, a book which, he says, should now be read "almost as historical documents". It had to be re-written in 1960 , when it was called Our Developing World, and some of the figures had to be brought up to date again for this paper-back edition.

Prof. Stamp sets the population explosion against a more stable background, that is, the amount of land available and the basic facts of climate and soil: these are the given elements from which man must obtain his food. But the relationship of man and land is by no means simple. The history of mankind is that of developing techniques to produce more and more food: cultivation, domestication, the invention of the hoe, the plough, the harnessing of power, rotation, irrigation, fertilizationall these have dramatically changed the relationship; and Prof. Stamp discusses the latest advances, mechan. ization and 'chemicalization', to show that potential changes are as great as those of the past. But another fact is equally evident: that this progression has been most uneven. Whereas revolutionized techniques enable advanced communities to produce the food they need with only a small percentage of primary producers, others are still at subsistence-level. Indeed, the majority of people are still setting the balance between Nature and society at starvation-level. Strangely enough, the more technologically advanced countries depend to an increasing degree on these same underdeveloped countries which supply, for example, much of the world's oil, most of its copper, tin and bauxite. The table of their contribution in this respect to the world's economy makes thoughtful reading.

Meanwhile, the problem of equating an exploding population with food supplies is of paramount importance, and demands all the skills of the most advanced technologies. Prof. Stamp's admirable little book puts these problems succinctly and clearly without pretending to attempt the answers. It gives the more general reader a real appreciation of the situation against a more geographical background than is usual. It cannot fail to make the reader conscious of the great dilemma of the age, and for this we are in debt to Prof. Stamp for one more expression of his concern with these problems.

EMRYS JONES 